\title{
GÊNERO, RAÇA E AVALIAÇÃO ESCOLAR: UM ESTUDO COM ALFABETIZADORAS
}

\author{
MARÍLIA PINTO DE CARVALHO \\ Professora do Departamento de Administração Escolar da Faculdade \\ de Educação da Universidade de São Paulo \\ mariliac@usp.br
}

\begin{abstract}
RESUMO
Este estudo pretendeu avaliar se a definição de objetivos pedagógicos claros e a consequente adoção de critérios de avaliação de aprendizagem bem delimitados poderiam minimizar os desequilíbrios socioeconômicos, de sexo e de raça, evidenciados no interior do grupo de alunos indicados para atividades de reforço por nove professoras alfabetizadoras de diferentes escolas públicas na cidade de São Paulo. Foram realizadas observações em sala de aula, entrevistas com as educadoras e formulados questionários de caracterização socioeconômica dos alunos. Conclui-se que: a maior alteração relativa a alunos e alunas de baixa renda se refere ao papel atribuído pela professora à recuperação, que passa a ser considerada não como punição, mas como oportunidade de aprendizagem; a presença majoritária no reforço de crianças percebidas como pretas, pardas e indígenas diminui ligeiramente pela melhor definição de critérios de avaliação escolar; é nítido o equilíbrio na indicação de meninos e meninas ao reforço quando se avalia com precisão a aprendizagem e não o comportamento. São feitas também indicações para a formação inicial e continuada de educadores/as no que se refere a relações de gênero e de raça. AVALIAÇÃO DE APRENDIZAGEM - GÊNERO - RAÇA - ENSINO FUNDAMENTAL
\end{abstract}

\section{ABSTRACT}

GENDER, RACE AND SCHOOL EVALUATION: A STUDY WITH LITERACY TEACHERS. This study aimed to verify if both the definition of plain educational goals and the adoption of clearly defined evaluation criteria could minimize inequalities at school, especially those related to socioeconomic, sex and race disparities noticed within a group of students referred to additional support activities by nine literacy teachers at different public schools in the city of São Paulo. The teachers were interviewed and the students answered a socioeconomic survey. Furthermore, observations within the schools were taken. The study concludes that the disproportionate number of children from low income families in that group is due to the particular role teachers attribute to those activities, which are considered not as a punishment, but as an opportunity to learn. Also, the incidence of black, mixed and native students is slightly reduced when evaluation

Pesquisa desenvolvida com apoio do Conselho Nacional de Desenvolvimento Científico e Tecnológico - CNPq. 
criteria are precise. Finally, it is easily noticed that girls and boys are equally referred when only the learning process is evaluated, and not behavior problems. Some indications to initial and continuing education of teachers are also made.

LEARNING EVALUATION - GENDER - RACE - PRIMARY EDUCATION

Nos últimos anos, tenho frequentado escolas, assistido aulas e entrevistado professoras do primeiro ciclo do ensino fundamental, em busca de explicações para a presença insistente, entre crianças de sexo masculino, de trajetória escolares mais truncadas, interrompidas por abandonos e repetências (Carvalho 200I , 2004, 2004a , 2005). Nessa busca, concentrei-me em tentar compreender os critérios de avaliação utilizados pelas professoras, pois percebo sua importância na determinação dos destinos escolares das crianças e pude constatar a grande dificuldade das equipes escolares para definir com clareza objetivos de aprendizagem e critérios de avaliação, uma dificuldade em verdade partilhada pelo conjunto do sistema escolar brasileiro e até mesmo no plano internacional. As professoras afirmavam avaliar os alunos com base em uma multiplicidade de instrumentos e diziam levar em conta tanto o desempenho propriamente dito, quanto o que denominavam "compromisso do aluno". Avaliar esse "compromisso", porém, era uma tarefa extremamente subjetiva, mesmo em escolas razoavelmente estruturadas e com espaços coletivos de discussão. Para fazê-lo, utilizavam repertórios e referenciais pessoais, apenas relativamente conscientes, sem perceber integralmente seu caráter arbitrário, e dessa forma reproduziam valores, ideias e símbolos decorrentes da hierarquia socioeconômica e das relações de gênero e etnorraciais. Assim, uma pergunta me acompanhava desde as primeiras fases da pesquisa: a definição de objetivos pedagógicos e critérios de avaliação de aprendizagem bem delimitados poderia minimizar os desequilíbrios socioeconômicos, de sexo e de raça evidenciados no interior do grupo de alunos indicados pelas professoras como portadores de dificuldades de aprendizagem?

Não se trata de reduzir problemas sociais e políticos a definições técnicas, supondo que um método pedagógico possa reverter as relações de poder na sociedade e na escola, mas apenas de indagar se e como o domínio teórico e prático de metas e de uma proposta pedagógica pode atuar no sentido inverso das desigualdades sociais de classe, gênero e raça, minimizando ou não seus efeitos sobre o desempenho escolar. Não há como negar que 
mesmo uma avaliação ancorada em objetivos curriculares resulta de escolhas culturais referidas à ideia de excelência escolar em vigor. Como nos aponta Phillipe Perrenoud (2003) "voltar ao currículo não resolve todos os dilemas quanto à definição do sucesso escolar, na medida em que ele próprio é objeto de controvérsias e interpretações divergentes" (p. 18), sendo os critérios de sucesso e fracasso escolar foco de disputa e negociação permanente entre os diferentes atores envolvidos, numa relação de poder desigual. Contudo, este autor sugere que "ater-se ao currículo e às suas finalidades é a única maneira coerente de colocar o problema dos critérios de sucesso" (p. l 8). E propõe a definição clara das finalidades da escola e dos critérios de avaliação como ferramenta indispensável na democratização do ensino.

No que se refere às diferenças entre meninos e meninas, foco deste estudo, há indicações na literatura internacional de que uma nítida separação entre avaliação de comportamento e avaliação de aprendizagem tende a diminuir o número de meninos indicados para classes especiais ou atividades de reforço, resultando em presença paritária entre os sexos, uma vez que, da mesma forma que nas escolas por mim estudadas, os meninos são considerados mais agitados, indisciplinados e dispersos (Connell, 2000; Lingard, Douglas, 1999; Jackson, 1998; Hey et al., 1998). Valerie Hey et al.( 1998), por exemplo, em estudo sobre atendimento a alunos com dificuldades de aprendizagem em quatro escolas primárias públicas de Londres, verificaram que a única em que havia números proporcionais de meninos e meninas nas atividades de reforço era a escola em que se colocava ênfase no sentido pedagógico desta ação, separando-a explicitamente dos problemas comportamentais, que eram enfrentados por meio de outras estratégias (p. 138).

Para verificar essa hipótese, foi desenvolvido um estudo qualitativo com nove professoras alfabetizadoras de quatro diferentes escolas. Escolhi centrar o estudo em professoras alfabetizadoras em primeiro lugar porque, no caso do primeiro ano da escola pública paulista', havia um amplo consenso de que sua finalidade era a alfabetização², ao lado de alguns rudimentos de soma e

I. A pesquisa foi realizada antes da ampliação por lei federal do ensino fundamental para nove anos, com a incorporação - a ser efetivada até 2010 - das turmas de pré-escola.

2. Utilizo, com base em Soares (2004), o conceito de alfabetização em seu sentido específico, como "processo de aquisição do sistema convencional de uma escrita alfabética e ortográfica" (p. I l), diferente de letramento, definido pela autora como "práticas sociais de leitura e escrita" (p.6). 
subtração. Assim, considerei que seria mais provável encontrar professoras nessa etapa da escolarização trabalhando com metas curriculares e critérios de avaliação bem definidos.

Em segundo lugar, têm alguma difusão na escola brasileira as assim chamadas teorias construtivistas e suas hipóteses sobre o processo de aquisição da escrita, o que pode dar em um suporte teórico à definição de critérios de avaliação da aprendizagem. Muitos são os estudos, além disso, que apontam "o construtivismo" como alternativa para diminuir os problemas de fracasso escolar e alcançar uma escola mais igualitária (Angelucci et al., 2004). Pareceume que seria rico dialogar com essa ideia, colocando no centro da pesquisa professoras alfabetizadoras consideradas por seus pares como bem-sucedidas e que adotassem, de acordo com sua própria declaração, o método ou a abordagem "construtivista". ○ objetivo, cabe enfatizar, não era verificar em que medida elas aplicavam adequadamente esses pressupostos teóricos, mas indagar se, uma vez tendo estabelecido critérios bem delimitados de avaliação, elas tendiam ou não a reproduzir desigualdades de sexo, raça e nível socioeconômico neste processo.

\section{AS ALFABETIZADORAS}

Cada professora foi entrevistada mediante um roteiro flexível, as famílias dos alunos responderam a questionário de caracterização socioeconômica e sempre que possível foram feitas observações complementares na classe ${ }^{3}$. As professoras foram convidadas a classificar todos os alunos de acordo com os critérios de raça/cor do Instituto Brasileiro de Geografia e Estatística - IBGE - (branco, preto, pardo, amarelo ou indígena) e a indicar aqueles que consideravam com dificuldades de aprendizagem, os que causavam problemas de disciplina assim como aqueles que consideravam como bons ou boas alunas. Quando havia algum tipo de atividade de reforço na escola, indagávamos quem eram os alunos indicados para essas atividades e por quê. Quando não havia esse tipo de apoio, perguntávamos quem elas indicariam caso houvesse um

3. Agradeço a Vivian Vitasovic de Alencar e Andréia Botelho de Rezende, bolsistas de Iniciação Científica da Faculdade de Educação da Universidade de São Paulo - Fe/Usp - e do CNPq, pelo apoio na parte empírica da pesquisa. 
reforço escolar. Em todos os casos, pelo menos uma outra professora alfabetizadora da mesma escola foi incluída entre os sujeitos da pesquisa, para que pudessem ser feitas comparações.

Ao final de dois anos, foram entrevistadas nove professoras de quatro diferentes escolas públicas da capital: Clara e Milene ${ }^{4}$ trabalhavam numa escola estadual em bairro de setores médios da Zona Oeste, com famílias de nível socioeconômico bastante diversificado (a única escola onde havia estudantes com renda familiar mensal acima de 20 salários mínimos) e que dispõe de prédios e equipamentos pedagógicos de boa qualidade, além de uma dinâmica intensa de trabalho coletivo entre seus professores. Marisa e Talma lecionavam em um bairro de setores médios e altos da Zona Sul, atendendo também um público relativamente diversificado, numa escola estadual bem equipada, porém com pouco trabalho coletivo. Na Zona Noroeste, em uma escola da rede municipal com boa infraestrutura, mas frágil trabalho coletivo, trabalhavam Jussara e Rebeca, com alunos que provinham tanto de uma favela próxima quanto de setores médios de baixa renda. Por fim, num bairro muito afastado do centro, na Zona Leste da Capital, encontramos Leila, Priscila e Meire, lecionando para crianças com rendas familiares bastante homogêneas, quase todas abaixo de cinco salários mínimos mensais, numa escola que dispunha de poucos recursos pedagógicos, funcionava em três turnos diários além de um noturno, e tinha classes com 40 alunos. Por meio de suas entrevistas, estas três últimas professoras nos permitiram perceber a importância do trabalho coletivo e da atuação da coordenação pedagógica naquela escola. Ao todo, foram envolvidas 310 crianças de I a série, consideradas as nove turmas estudadas.

Além da diversidade de suas condições de trabalho e das condições socioeconômicas das famílias de seus alunos, o grupo de entrevistadas tinha poucos pontos em comum em termos de idade, tempo de experiência no magistério e formação. Marisa, Talma e Jussara contavam com mais de vinte anos de trabalho como professoras de ensino fundamental; Meire, Priscila, Leila e Clara tinham menos de cinco anos de experiência; Milene e Rebeca contavam com dezessete e quatorze anos respectivamente. A maioria fizera Curso de Magistério e curso de nível superior, sete delas em Pedagogia. Clara tinha também curso de mestrado em Educação e Talma concluíra no ano anterior à

4. Todos os nomes de pessoas e instituições são fictícios. 
pesquisa, um curso de formação em serviço parcialmente a distância (dezoito meses), seu único diploma de nível superior.

Três das professoras (Milene, Meire e Priscila) haviam frequentado em turmas diferentes, um curso de formação continuada organizado pela Secretaria de Ensino Fundamental do MEC em convênio com prefeituras e redes estaduais o - Programa de Formação de Alfabetizadores - Profa. As propostas desse curso eram referências constantes em nas falas, assim como da coordenadora pedagógica da escola da Zona Leste, que reproduzia algumas das atividades deste programa nas reuniões, o que decerto influenciava também a Leila, professora no mesmo local. Este parece ser um dos poucos pontos em comum entre parte dessas educadoras, embora deva-se destacar que, por um lado, Milene não conhecia as colegas que trabalhavam na Zona Leste, e por outro, as falas de Talma eram muito semelhantes às delas, embora não as conhecesse nem houvesse participado do Profa. Mais do que uma referência específica a um curso de formação, trata-se, ao que parece, de uma referência comum a uma leitura da psicogênese da língua escrita, tal como foram difundidas no Brasil as teorias de Emilia Ferreiro e Ana Teberosky.

Todas as professoras se autoclassificaram como brancas, com exceção de Jussara que se classificou como preta. Jussara foi também a única a criticar a tabela apresentada pelas entrevistadoras por escrito para essa classificação, baseada nos critérios do IBGE: "Não é preto, é negro. Não é negro? [...] O preto é cor de alguma coisa: cor da sua bolsa, não cor de raça." Contudo, ao ser solicitada a classificar as crianças pelos mesmos critérios, Jussara não retomou qualquer dessas críticas e fez a classificação utilizando inclusive os termos preto e pardo.

\section{"A gente está usando as fases de escrita"}

O primeiro elemento que se mostrou decisivo nas formas de avaliação adotadas por essas alfabetizadoras refere-se ao conhecimento e utilização, como único critério de avaliação escolar, das hipóteses definidas pelas teorias da psicogênese da língua escrita. Respondendo à questão sobre quem indicaria para atividades de reforço, Priscila por exemplo, descreveu sua turma no início daquele ano letivo: "Quando começou o ano, eu tinha cinco alunos alfabéticos. Eu tinha 18 alunos em hipótese pré-silábica, oito alunos em hipótese silábica 
sem valor e só oito alunos com hipótese silábica com valor... eles não foram alfabetizados na pré-escola" (Priscila).

Nesse grupo de professoras poderíamos incluir Talma, Milene, Priscila, Leila e Meire. É importante destacar que essas professoras, além de conhecerem individualmente os processos de alfabetização vividos por cada um de seus alunos e alunas, estavam também atentas aos aspectos comportamentais, que elas conheciam, descreviam e sobre os quais procuravam atuar para construir uma postura que consideravam adequada.

Priscila e Meire chegaram a elaborar uma ficha de avaliação apresentada aos pais em reuniões bimestrais, composta por dois quadros. No primeiro quadro, podia-se acompanhar mês a mês a hipótese de escrita em que estava a criança. No segundo, são respondidas com "sim" ou "não", questões como: "Tem um bom nível de atenção? É cooperativo com os colegas e professora? Respeita os combinados de boa convivência em sala de aula?", entre outras. Elas relataram explicar aos pais, em todas as reuniões, o significado de termos como "pré-silábico" e "silábico com valor" e que não estavam atribuindo notas ou conceitos aos alunos.

Aspectos do relacionamento entre as crianças foram enfatizados em diferentes momentos das entrevistas de todas essas professoras: "Eles são afetivos. É uma classe... eles são muito participativos... muito bagunçeiros [risos]. Mas é uma classe unida, é bonito ver a união dessas crianças. Não existe rixa com as crianças, ninguém menospreza ninguém dentro da sala. É um ambiente muito legal" (Talma).

E elas falaram da dificuldade de obter concentração e construir rotinas de trabalho, em especial devido ao tamanho das turmas, ao tipo de trabalho que desenvolviam e à ausência de auxiliares:

Quarenta crianças, agitadíssimas, muito faladores, eles bagunçam mesmo [risos]. Não encontrei ainda uma solução para isso, mas também uma classe de 40 alunos de sete anos fica bem difícil. Ainda mais do jeito que a gente trabalha, com grupos, textos coletivos. [...] Então, a gente está buscando este equilíbrio ainda, mas eu saio esgotada da sala. (Priscila)

Todas revelaram um conhecimento individualizado de cada aluno também quanto às condições familiares, de vida, de saúde, atividades fora da escola: "O 
V. está silábico-alfabético também, está quase lá, mas a mãe dele ficou grávida agora. Ele tem 7 anos e agora que a mãe dele ficou grávida, então ele teve uma recaída, mas eu acho que até o final do ano ele volta ao normal". (Leila).

No caso dessas professoras, as condições, quase sempre difíceis ou precárias, não eram invocadas para justificar impossibilidades nem como barreiras para a atuação pedagógica, ainda que se possa reconhecer nas falas preconceitos sobre "famílias desestruturadas", sempre que a unidade familiar não correspondia ao modelo nuclear completo. Essas situações eram consideradas apenas como pano de fundo para entender as dificuldades dos alunos e, muitas vezes, como afirmação de que essas eram as crianças que mais precisavam delas, tanto para aprender quanto para construir uma postura adequada de aluno, como diz Talma:

Eu acho que cada criança tem um ritmo, ela tem uma história de vida, assim, diferente, né? Às vezes ela conta exclusivamente com a escola, com o professor, com os colegas de classe. A família é pouco presente na vida escolar do aluno: a mãe trabalha fora, o pai trabalha fora. Às vezes a mãe vê a criança à noite. Então, eu acho que o importante é você saber de tudo isso, [...] saber a hipótese que essa criança está trabalhando, compreender isso, pra você poder auxiliar. (Talma)

Não se tratava, portanto, de professoras que desconhecessem aspectos não cognitivos da vida escolar e mesmo extraescolar de seus alunos, mas de professoras que priorizavam nos critérios de avaliação elementos ligados ao currículo, à aprendizagem escolar:

Por que, senão, a gente teria muitas outras coisas para medir nessa hora. Ficaria mais difícil. Então a gente teria que prestar atenção assim: "Ah, este aluno está alfabético, mas ele bagunça, não tem um bom relacionamento". Não, no nosso critério, a gente está usando a hipótese de escrita, porque é nisso que a gente coloca nossas forças. (Priscila)

\section{"A gente avalia a criança como um todo"}

De maneira contrastante, as demais professoras afirmavam incluir um conjunto amplo de elementos ligados à postura e ao comportamento em sua 
avaliação, tanto no que se refere à atribuição de conceitos, quanto à indicação, durante a entrevista, das crianças que precisariam de atividades de reforço. Marisa e Clara não utilizaram em qualquer momento as hipóteses de escrita como critérios de avaliação, referindo-se às crianças apenas como "alfabetizadas" ou "não alfabetizadas" ou ao fato de "já saberem ler". Essas duas professoras utilizavam critérios bastante vagos e amplos na avaliação das crianças, em geral referindo-se a seu comportamento e ao suporte familiar de que dispunham:

A nossa avaliação é contínua, diária, né? A gente tá avaliando não só a parte pedagógica, o que o aluno faz, mas também os valores, o que ele traz de casa... Tudo isso, o dia-a-dia dele, desde a hora que ele já está lá em formação para vir para a sala de aula, até a hora da saída. (Marisa)

Já Jussara e Rebeca se referiam a seu trabalho pedagógico e a seus alunos muitas vezes a partir das hipóteses de escrita, que identificavam como "fases" ou "estágios": "Quando a gente prepara a atividade com determinada letra ou tema, a gente pensa na criança que está na fase pré-silábica, silábica, em todas as fases" (Rebeca).

Essas professoras demonstraram conhecimentos a respeito das hipóteses de escrita, chegando até mesmo a elaborar quadros com o conjunto de seus alunos que indicavam passo a passo, ao longo do ano, a hipótese em que estariam, de maneira semelhante aos realizados por Priscila e Meire. Entretanto, apesar disso, Jussara e Rebeca não colocavam essas "fases" no centro de sua avaliação das crianças, na qual predominavam questões amplas, de ordem comportamental, emocional, familiar ou até mesmo de saúde, aproximando suas falas daquelas das professoras que não se referiam às hipóteses de escrita: "A gente conta muito o todo da criança: a participação em sala, com as atividades, caderno, relacionamento entre amigos, o relacionamento da criança com os funcionários da escola. Tudo isso é levado em conta na avaliação"(Rebeca).

Dessa forma, seria possível dividir as nove professoras em dois grupos, de acordo com seus critérios de avaliação: um primeiro grupo que utilizava como único critério, para atribuição de conceitos ou indicação a atividades de reforço, a hipótese de escrita em que a criança estaria; esse grupo incluía cinco alfabetizadoras de três diferentes escolas: Milene, Talma, Meire, Priscila e Leila; e um segundo grupo que, mencionando ou não estas "fases", utilizava como 
critério uma visão global do aluno ou aluna, aí considerados aprendizagem, comportamentos, atitudes, problemas familiares etc. Nesse segundo grupo seriam incluídas Clara, Marisa, Jussara e Rebeca.

\section{“Mas o que é um bom aluno?"}

Outro aspecto, contudo, também se mostrou relevante nas falas das professoras sobre os alunos. Quatro das alfabetizadoras do primeiro grupo - Talma, Milene, Meire e Priscila -além de procurar utilizar as hipóteses de escrita como único critério de avaliação, recusaram uma lógica classificatória, questionando as entrevistadoras sobre a possibilidade de indicar "bons ou maus alunos" e reafirmando o potencial de todas as crianças. É muito expressiva desse movimento a postura de Talma que, ao ser indagada ao final da entrevista, se tinha mais alguma coisa a comentar, retomou a classificação que fizera dos alunos e questionou a própria lógica da pergunta:

Quando você fala "quem você considera bom aluno", "o que é um bom aluno pra você?" Eu acho que é uma pergunta... Você direciona a pessoa a fazer um conceito disso daí, né? [...] [Você ficou incomodada com essas perguntas?] Sim, incomodada com essa pergunta, com esse "bom", entendeu? Eu acho, assim, que na verdade, vocês me induziram a colocar um conceito. [...] Porque não vai existir o mau aluno. Não existe isso, do mau aluno. Tirar "d", tirar "e": não tem. $O$ aluno quando traz a lição pra você ver, ele produziu o melhor que ele pôde. É aquilo que ele acha que é. Cabe a você fazer essa criança progredir, aprender, cabe ao professor. (Talma)

Ao final dessa conversa, Talma, que havia assinalado alguns alunos e alunas de sua classe como "bons", retomou a lista e marcou todos como "bons", reafirmando: "Todos os alunos são bons". Sua fala também destaca o incômodo dessa professora, partilhado pelas demais citadas, com a necessidade de atribuir conceitos às crianças, necessidade com a qual cada uma delas lidava de formas diferentes, conforme o contexto da escola e as possibilidades de acomodação entre suas convicções e as exigências burocráticas, como Meire e Priscila, que elaboraram uma ficha de avaliação própria, "sem notas", a ser apresentada aos pais. 
Também a entrevista feita simultaneamente com Priscila e Meire resultou em uma conversa muito rica a respeito das exigências burocráticas de atribuir conceitos e dessa lógica classificatória, de mérito, que faz parte do senso comum em vigor nas escolas:

Priscila: Bons alunos? Eu vou apontar os que gostam de estudar. [risos] $\bigcirc$ que é um bom aluno? Ai, meu Deus! É que a gente tem aquela coisa, a gente acredita, a gente quer acreditar em todos, né? Mas quando você faz uma pergunta dessas. Ai, meu Deus do céu!

Meire: Agora, este bom aluno que você está perguntando, é o bom aluno no ambiente escolar? [É o que vocês entendem por bom aluno.] Bom aluno? A S. é silábica sem valor e eu acho a $S$. ótima. Ela é uma menina que sabe respeitar um ambiente público, ela é muito delicada comigo, delicada com os colegas, ela é minha aluna mais... [faz gestos de carinho com as mãos]. Ai, é muito difícil! [...] Pode ficar sem responder a pergunta?

Priscila: Muitos são bons alunos... é muito difícil. Eu sei daqueles que precisam de mais ajuda. Porque eu não dou conta em uma sala de 40, de estar com eles individualmente, ficam 39 precisando de mim, gritando pela sala. Então, eu sei destes, que eu gostaria que tivessem um reforço para poder ter uma atenção mais individualizada, porque eu acho que eles merecem, mesmo pelo aproveitamento deles, pelo que eles avançaram. Eu diria que é uma sala boa. São alunos bons [risos].

A pergunta que incomodou a essas professoras foi a solicitação de que indicassem quem eram "bons ou boas alunas". Enquanto as demais responderam sem hesitar, Milene, Talma, Priscila e Meire ensaiavam fazê-lo, recuavam, mostravam dúvida e incômodo. Ao assumir esse tipo de posição, elas estavam questionando a lógica das perguntas feitas pelas entrevistadoras. Isso implicava uma atitude de contestação à relação de autoridade entre entrevistadora e entrevistada, no quadro daquilo que Bernard Lahire (2003) chama de "efeito de legitimidade" (p.75). E o grau e facilidade com que foi feita essa contestação variaram, a meu ver, conforme a segurança da professora diante dessa situação de poder e as condições da entrevista, e não apenas de acordo com convicções e práticas.

O fato de não se incomodarem nem terem dúvidas ao indicar os alunos "que precisariam de reforço" parece decorrer de que essa classificação não 
implicava uma hierarquia ou um sentido de valor, mas o reconhecimento de que essas crianças poderiam desenvolver-se melhor caso houvesse um trabalho específico dirigido a elas (já que na maioria das escolas pesquisadas não havia reforço nas turmas de $\mathrm{I}^{\mathrm{a}}$ série). As quatro alfabetizadoras tinham muita clareza de que essas crianças, mais do que as outras, dependiam da escola e das professoras para adquirir tanto conhecimentos escolares quanto hábitos e comportamentos adequados como estudantes, segundo expressou Talma, falando de uma de suas alunas:

Ela é estimulada aqui na escola, na classe, você está estimulando aquilo. Mas ela chega em casa, não tem ninguém que se interesse pela vida escolar dessa criança. Ela não tem ninguém para mostrar aquilo que ela produziu. Há esse desinteresse total. [...] Agora, quem tem de fornecer esse recurso, se ela não tem? É a escola, é o professor. Não digo todos, porque você não vai ficar com essa criança o tempo todo. Mas durante o período que ela está aqui na escola, você tem que pelo menos tentar suprir isso daí. (Talma)

Todas essas professoras tinham algum tipo de dificuldade e críticas em relação aos conceitos que eram obrigadas a utilizar na avaliação formal dos alunos, conceitos que tão bem sintetizam a lógica classificatória da escola. Embora o incômodo com a atribuição de conceitos em fichas formais fosse generalizado entre todas as entrevistadas, para as demais a questão eram as dúvidas sobre como utilizá-los, às vezes levando à sugestão de que não fossem apenas três (NS, S e PS). Não havia a ideia de sua supressão. Assim, poderíamos formar um subgrupo composto por Milene, Talma, Priscila e Meire, professoras que recusavam abertamente o sentido hierarquizador da classificação de seus alunos por meio de notas ou conceitos.

Finalmente, as falas de duas professoras em particular foram desafiadoras quanto à formação desses agrupamentos. Leila, que trabalhava ao lado de Meire e Priscila na escola da Zona Leste, utilizou as hipóteses de escrita como forma de avaliação de seus alunos indicados para um eventual reforço. Contudo, ao ser indagada sobre quem seriam seus "bons alunos e alunas", não hesitou, perguntando apenas: "Pode ser caracterizado como os melhores da sala?". Em seguida marcou com um "B" 23 de seus 39 alunos. Quanto ao critério dessa indicação, esclareceu: "Todas as atividades que a gente pede eles conseguem 
realizar, já estão alfabéticos". Assim, embora não tenha recusado a possibilidade de indicar "bons alunos", Leila classificou quase 60\% de sua classe como parte desse grupo e ofereceu explicações ligadas apenas à aprendizagem para essa avaliação. Deve-se observar, contudo, que sua entrevista foi uma das mais curtas e ela aparentemente tinha pouco a dizer. Começara apenas aquele ano a trabalhar na mesma escola que Priscila e Meire e adotava até mesmo em suas fichas formais de avaliação a classificação dos alunos por hipóteses de escrita e, ao contrário de suas colegas, que foram ouvidas em dupla, Leila foi entrevistada sozinha. Ela fizera curso superior de Matemática e não frequentara qualquer curso de formação específico sobre alfabetização como o Profa, diversas vezes mencionado por suas colegas. Tudo isso pode tê-la deixado menos à vontade para assumir uma postura crítica diante das perguntas da entrevista, e pode tê-la induzido a apenas classificar as crianças conforme solicitado.

Por sua vez, Rebeca, que trabalhava na escola da Zona Noroeste, recusou-se a indicar alunos para o reforço, caso houvesse esse tipo de atividade em sua escola, por ainda estarmos em abril. Isso poderia nos levar a incluí-la entre as professoras que recusavam todo tipo de hierarquização entre seus alunos. Entretanto, Rebeca não demonstrava qualquer problema com relação à atribuição de conceitos às crianças e, quando solicitada a indicar "os bons alunos e alunas", respondeu: "Bons em matéria de tudo, de comportamento, de rendimento escolar, são esses aqui", marcando 13 nomes na lista de chamada. À pergunta sobre qual critério usara para classificá-los, respondeu sem hesitação: "Eu vejo a participação em sala de aula, o interesse, se trouxe a lição de casa, se está com o caderno completo, se ela se relaciona bem com os amigos da sala de aula". Assim, concluí que Rebeca não poderia ser incluída entre as professoras que recusavam a lógica hierarquizadora do ensino escolar. A fim de conhecer melhor sua classificação das crianças, voltei à escola no ano seguinte e registrei as avaliações que ela atribuíra a seus alunos e alunas, utilizando as informações nas tabelas e gráficos que se seguem. Quanto a Leila, preferi mantê-la no grupo de professoras mais voltadas à avaliação de conteúdos curriculares, porém dedicando especial atenção aos resultados de sua classe. Trabalho a seguir, portanto, com dois grupos de professoras: Milene, Talma, Priscila, Meire e Leila, que comporiam o Grupo I, o qual utilizava critérios bem definidos de avaliação; Clara, Marisa, Rebeca e Jussara, o Grupo 2, com critérios vagos. 


\section{Renda e desempenho escolar: "ele já nasceu A!"}

A pesquisa forneceu indicações limitadas sobre as relações entre a situação socioeconômica das famílias e o desempenho escolar das crianças conforme avaliado pelas professoras. Em primeiro lugar, porque foram altos os índices de questionários não devolvidos pelos alunos e em segundo lugar porque, devido a problemas em algumas das cópias e à dificuldades das famílias em compreender as perguntas relativas à escolaridade dos responsáveis, pude dispor apenas dos dados relativos à renda familiar, que são um indicador precário da situação socioeconomica. Ainda assim, por ser este um dos temas mais amplamente estudados no que se refere ao desempenho escolar, considero ser possível avançar algumas afirmações.

A primeira delas diz respeito ao alto índice de coincidência entre a não resposta ao questionário e a indicação para reforço: em todas as classes de ambos os grupos de professoras, a proporção de "não respostas" entre as crianças indicadas para reforço é mais alta que no conjunto da turma ${ }^{5}$. A meu ver, isso decorreria de três situações correlacionadas: muitas das crianças foram indicadas para reforço devido a um grande número de faltas, o que pode tê-las levado a estar ausentes, seja no dia da entrega dos questionários, seja no dia em que deveriam devolvê-lo; em segundo lugar, provinham de famílias de baixa escolaridade muitos dos alunos que as professoras, mesmo aquelas do Grupo I, avaliaram como necessitando de um apoio específico, e essas famílias podem ter tido dificuldade de ler e responder o questionário; e, por fim, depreende-se das entrevistas que muitas das famílias de crianças indicadas como portadoras de dificuldades de aprendizagem eram exatamente aquelas mais ausentes da vida escolar ou que pelo menos apresentavam uma relação frágil e pouco frequente com a professora, o que pode ter incluído a recepção e resposta ao questionário. Situações como essas foram relatadas por educadoras de todas as escolas e dos Grupos I e 2, em relação aos alunos que indicariam para reforço.

Em segundo lugar, a tendência em quase todas as classes era de uma maior proporção de alunos de baixa renda no grupo indicado para reforço, sem que se possa fazer uma diferenciação entre escolas, entre tipo de ava-

5. Com exceção da sala de Milene, em que todas as crianças retornaram o questionário. 
liação adotada pela professora ou mesmo entre aquelas professoras que se recusaram a indicar bons alunos e as demais. Com exceção de Marisa, todas as demais professoras percebiam que as crianças provenientes de famílias de mais alta renda tendiam a ter menos dificuldades no processo de alfabetização ${ }^{6}$. A interpretação do papel da alfabetizadora perante a dificuldade é que variava profundamente.

grupo de professoras que avaliava "o aluno de forma global" e que aceitou classificar parte de seus alunos como "bons", sem críticas à hierarquia assim estabelecida, esperava e cobrava das famílias, em especial das mães, uma participação na escolarização dos filhos que a professora não poderia suprir, e cuja ausência atrapalharia "o rendimento", isto é, a aprendizagem das crianças:

Não participam de reunião, não querem nem saber, não se envolvem, não estão envolvidos com o dia a dia do filho, sabe? Tudo bem que eu sei que às vezes eles têm que correr atrás do pão de cada dia deles, eles têm que garantir uma forma de melhoria dentro da casa deles, mas fica difícil também pra gente essa ausência da família. A ausência da família é muito negativa diante do quadro que você vê, diante do rendimento deles. (Marisa)

Em outras falas a questão é percebida como "problema social":

E eu tenho muito problema social lá dentro da minha sala, demais. Isso não é o ponto principal, mas é um ponto que influencia no rendimento da classe toda. [Quais são esses problemas?] Eu tenho uma aluna adotada, a mãe teve essa menina quando ela estava presa. Eu tenho um aluno que não mora com a mãe de segunda a sexta, e só vê a mãe de sábado e domingo. [...] Eu tenho crianças que ficam na rua o dia inteiro, o caso de uma mãe que está envolvida com drogas. Estes casos são os que eu descobri. (Rebeca)

Além de designar um lugar específico às mães na educação das crianças, as falas de professoras do Grupo 2 reproduzem pressupostos do senso comum

6. Deve-se observar, contudo, que o índice de não resposta na classe de Marisa foi de $28 \%$, o que corresponde a 9 alunos, sendo que 4 deles foram indicados para o reforço. 
entre educadores escolares a respeito do "desinteresse das famílias" e da inevitável existência de problemas quando a estrutura familiar não corresponde à nuclear completa, um conjunto de ideias já bastante estudadas no Brasil e em outros países (apenas a título de exemplo, podemos citar Patto, 1990 e Lahire, 2003). Embora esses preconceitos estivessem presentes também nas falas das demais professoras, eles me pareceram mais explícitos nesse grupo e foram utilizados como explicação para os problemas de aprendizagem das crianças, diferentemente das professoras do Grupo I.

Em algumas falas, em especial quando as professoras que aceitaram fazê-lo descreviam seus "bons alunos", a questão do capital cultural das famílias apareceu de forma explícita, em geral por meio de termos como "repertório" ou "bagagem" que a criança traz de casa:

O C., ele é uma criança que também os pais dão muita..., têm muito acesso a essa questão de cultura, de cinema, de teatro, de viagem. Ele conta coisas do Pantanal porque há uns dois anos atrás ele viajou para o Pantanal. São vivências que eles acabam trazendo e que fazem diferença. (Clara)

\section{"Eu sei daqueles que precisam mais de mim"}

Já para o grupo de professoras que se recusou a indicar "bons alunos" e revelou um discurso articulado contra o caráter hierarquizador da atribuição de notas, as dificuldades das crianças de baixa renda apareciam como motivos para que elas se empenhassem mais, para que oferecessem mais atenção, eventualmente indicando essas crianças para atividades de reforço. Não se tratava de uma hierarquia, mas de uma espécie de "ação afirmativa", um apoio extra àquelas crianças que, se tratadas de forma homogênea, não teriam condições de se desenvolver tanto quanto as demais, mesmo que em ritmo mais lento. É a mesma ideia que destacamos, quando sublinhamos em uma fala de Priscila a afirmação: "eu sei desses que precisam mais de mim".

Talma utilizou a comparação entre dois de seus alunos, Daniel e Larissa, provenientes de famílias com escolaridade e situação socioeconômica bem diversas, para, no final da entrevista, sintetizar um ponto de vista sobre a arbitrariedade do sistema de avaliação escolar e sua estreita articulação com a desigualdade socioeconômica: 
O Daniel, a mãe é professora, o pai fez Engenharia. Eu tenho certeza que a mãe é super presente, se interessa pela vida escolar dele. [...] Então o Daniel tem outros recursos que a Larissa, por exemplo, não tem. Agora, quem tem de fornecer esse recurso, se ela não tem? É a escola, é o professor! [...] O Daniel, a mãe lê todos os dias pra ele. Então o vocabulário desse menino é mais rico, ele já tem livros de histórias. Essa menina tem o quê? [...] A trajetória dessa menina, pra ela se alfabetizar, pra ela começar a ler, compreender, interpretar, vai ser mais difícil, mais lenta. E essa menina, eu vou dar o quê pra ela? Eu vou dar um "e", um "d"? Tá certo? Não tá. Eu vou dar "a" pro Daniel? Ele já nasceu "a", ele tem toda ajuda, todo recurso possível. (Talma)

Acredito ter indicações suficientes, portanto, de que a percepção da arbitrariedade da avaliação escolar, assim como a recusa das hierarquias que ela estabelece podem romper com a reprodução de desigualdades socioeconômicas no âmbito da avaliação de desempenho na escola. Não basta avaliar com critérios referidos a conteúdos de aprendizagem: é preciso questionar a própria necessidade e possibilidade de classificar os alunos e alunas em "bons", "medianos" ou "maus". É preciso atribuir à avaliação um sentido pedagógico, de diagnosticar o trabalho desenvolvido, chamando para a escola a responsabilidade pela aprendizagem de cada criança, principalmente aquelas que mais dependem da instituição para ter contato sistemático com a linguagem escrita e a cultura escolar em geral. Os bons resultados obtidos por Milene, Talma, Priscila e Meire com a maioria de seus alunos e alunas, incluindo os de mais baixa renda, ressaltam que a escola pode ajudar a minimizar as desigualdades socioeconômicas, seja ao recusar uma hierarquização das crianças, seja ao oferecer oportunidades de aprendizagem mais intensas àquelas que mais precisam, deixando de considerar a indicação para o reforço como um problema e percebendo-a como uma possível solução.

\section{Raça e desempenho escolar: "não existe uma discussão feita"}

Analisando os dados sobre as nove classes tomadas uma a uma, percebemos que em apenas três delas a proporção de crianças brancas, de acordo com a heteroclassificação feita pela professora, era maior ou igual no grupo indicado para reforço e no conjunto da turma (classes de Talma, Priscila e Leila), sendo que apenas na turma de Priscila observou-se uma diferença significativa. Rebec- 
ca e Meire por sua vez embora tenham classificado praticamente a metade da classe como brancos, só percebiam negros ${ }^{7}$ e indígenas no reforço. Se, contudo, somarmos o total de alunos e alunas das classes de acordo com os grupos de professoras, percebemos que no grupo daquelas que apresentavam critérios bem delimitados de avaliação (Grupo I), a proporção de crianças brancas e negras nas classes e no reforço é muito semelhante (Fig. I). ${ }^{8}$ Em contraste, a soma das classes do grupo de professoras que "avaliavam a criança como um todo" (Grupo 2) revela maior proporção de crianças negras e indígenas entre as indicadas para o reforço (Fig. 2). Além disso, as professoras deste grupo classificaram uma proporção muito maior de alunos como indígenas (num total de 122), embora nenhuma das escolas atendesse a grupos socialmente identificados como tal.

Concluímos portanto que a existência de critérios bem delimitados de avaliação de aprendizagem tende a equilibrar a proporção de crianças indicadas para reforço escolar no que se refere ao pertencimento racial atribuído, porém isso ocorre de maneira pouco definida e, como veremos adiante, menos nítida se comparada a seu efeito sobre a diferença entre meninos e meninas.

FIGURA I

GRUPO I- CLASSES E REFORÇO EM NÚMEROS ABSOLUTOS DE ACORDO COM A RAÇA ATRIBUÍDA

\begin{tabular}{l|c}
\hline & Classe \\
\hline Brancos & 119 \\
\hline Negros & 62 \\
\hline Indígenas & 0 \\
\hline Total & 181 \\
\hline
\end{tabular}

Classe x Raça atribuída

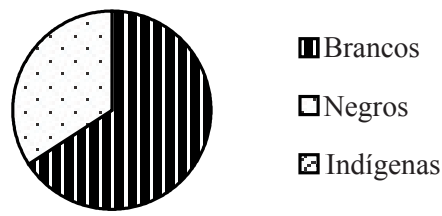

\begin{tabular}{l|c}
\hline & Reforço \\
\hline Brancos & 31 \\
\hline Negros & 13 \\
\hline Indígenas & 0 \\
\hline Total & 44 \\
\hline
\end{tabular}

Reforço x Raça atribuída

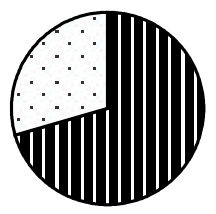

7. Soma dos alunos classificados como "pretos" e "pardos".

8. Nenhuma professora desse grupo classificou qualquer de seus alunos como "indígena". 
FIGURA 2

GRUPO 2 - CLASSE E REFORÇO, SEGUNDO A RAÇA ATRIBUÍDA AO ALUNO

\begin{tabular}{l|c}
\hline & Classe \\
\hline Brancos & 72 \\
\hline Negros & 42 \\
\hline Indígenas & 8 \\
\hline Total & 122 \\
\hline
\end{tabular}

'Classe x Raça atribuída

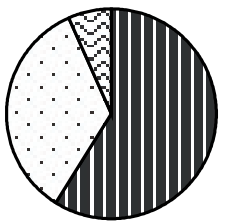

\begin{tabular}{l|c}
\hline & Reforço \\
\hline Brancos & 13 \\
\hline Negros & 15 \\
\hline Indígenas & 2 \\
\hline Total & 30 \\
\hline
\end{tabular}

Reforço x Raça atribuída

$$
\begin{aligned}
& \text { 凹Brancos } \\
& \square \text { Negros } \\
& \text { Ⓘndígenas }
\end{aligned}
$$

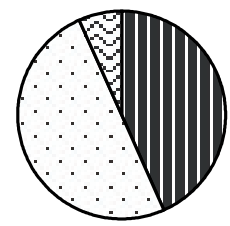

Todas as professoras mostraram incômodo para classificar seus alunos do ponto de vista racial e declararam tomar como critério a cor da pele, traços faciais e tipo de cabelo. Algumas mencionaram também informações dadas pela criança sobre sua ascendência e a visão que tinham de seus pais ou mães:

Eu fui pela cor da pele [rindo], que eu os identifico pela cor da pele. E eu não tenho em mãos a certidão de nascimento, que seria, acho, o mais correto, não é? E eu fui, então, pelo que eu conheço, lembrando dos pais também, que eu já conheço, então eu fui classificando por aí. (Marisa)

Como vimos, apenas Jussara, a única professora que se autoclassificou como negra, apresentou questionamentos aos critérios do IBGE. Porém, as dúvidas e a percepção de que a mesma criança poderia ser classificada por outra pessoa de maneira diferente estiveram presentes em muitas entrevistas, tal como na fala de Marisa, que mencionou a certidão de nascimento como fonte confiável.

Eu enxergo eles assim. Engraçado que não bate em nada com os que os pais dizem. A gente fez um questionário deste na escola. Justamente os que a gente acha que são pardos, os pais falam que são negros. Os que a gente acha que são 
negros os pais colocam brancos. A maioria dos pardos os pais colocaram brancos. Eles enxergam que o filho é branco. (Priscila, comparando com o questionário do Censo Escolar 2005)

Embora revelem uma reflexão inicial sobre as ambiguidades da questão no Brasil, essas dúvidas e questionamentos não resultavam de debates e reflexões sistemáticas no âmbito das escolas, como declararam todas as professoras: "A gente vai fazendo e a gente não pára muito para pensar no que pode ser. [...] Não existe uma discussão feita e uma conclusão tirada" (Clara). As situações relatadas se referiam geralmente a atitudes individuais de alguma professora, que buscava discutir com os alunos as diferenças e discriminações em geral:

A gente costuma trabalhar a diversidade na sala de aula de uma maneira lúdica, praticamente, através de características físicas, pessoais, valorizando a diferença, sem a discriminação. Valorizando que cada um..., que bom que cada um é diferente, que cada um tem seu valor dentro de um grupo e cada um tem o seu lugar dentro de um grupo. (Rebeca)

No que se refere, à percepção das professoras sobre indisciplina, as alfabetizadoras reunidas no Grupo 2, que utilizavam critérios amplos de avaliação, tenderam a apontar um maior número de crianças indisciplinadas e de forma muito mais acentuada no grupo de alunos percebidos como negros e indígenas.

Como indicam as tabelas da figura 3, as professoras do Grupo I apontaram como indisciplinadas $7,6 \%$ das crianças que classificaram como brancas e $4,8 \%$ das classificadas como negras. Já as professoras do Grupo 2 apontaram problemas disciplinares em $9,7 \%$ das crianças que percebiam como brancas, em 19, 1\% das vistas como negras e 37,5\% das percebidas como indígenas. Destaque-se que eram de sexo masculino $80 \%$ de todos os classificados como indisciplinados.

Apesar de existirem variações expressivas quando consideramos os dados classe a classe, é possível perceber a presença mais intensa entre as professoras do Grupo 2 de um quadro de referência que associa masculinidade negra e indígena a comportamentos indisciplinados. Por tudo isso parece que as professoras do Grupo 2, menos críticas do sistema de avaliação escolar como um todo, assim como de seu papel na reprodução das desigualdades 
socioeconômicas, também eram mais susceptíveis a reproduzir as desigualdades raciais e os pressupostos associados à masculinidade nãobranca, contrastando até mesmo com os resultados que obtive em pesquisas anteriores (Carvalho 2004, 2004a, 2005).

FIGURA 3

CLASSE E INDISCIPLINA NOS GRUPOS I E II, SEGUNDO A RAÇA ATRIBUÍDA AO ALUNO

\begin{tabular}{l|c|c|c}
\hline GRUPO 1 & Classe & Indisciplinados & $\%$ \\
\hline Brancos & 119 & 9,0 & 7,6 \\
\hline Negros & 62 & 3,0 & 4,8 \\
\hline Indígenas & 0 & 0,0 & 0,0 \\
\hline \multicolumn{4}{|l}{} \\
\hline GRUPO 2 & Classe & Indisciplinados & $\%$ \\
\hline Brancos & 72 & 7,0 & 9,7 \\
\hline Negros & 42 & 8,0 & 19,1 \\
\hline Indígenas & 8 & 3,0 & 37,5 \\
\hline
\end{tabular}

Mais ainda, se as diferenças entre os grupos I e 2 estão pouco relacionadas aos critérios de avaliação e mais à capacidade crítica das professoras, pode-se afirmar que, para reverter esse quadro, é necessário informá-las e capacitá-las no que tange às relações raciais no Brasil, para que as discutam de maneira planejada e constante com suas classes e saibam enfrentar situações de preconceito e discriminação entre as crianças.

\section{Sexo e desempenho escolar: "além de ter indisciplina, ele é agressivo"}

Os dados das classes cujas professoras declararam utilizar como critério exclusivo de avaliação as hipóteses de escrita (Grupo I) revelaram uma tendência bem definida em todas as turmas de um número proporcional de meninos e meninas, nos grupos de reforço e, em alguns casos, maior proporção de meninas. A única exceção foi a sala de Leila, com mais meninos no reforço, o que tanto pode ser creditado a um mero acaso, quanto às características desta professora. Somadas todas as crianças atendidas por essas professoras, o 
agrupamento resultante mantém a tendência de igual proporção de cada sexo nas classes e no reforço (Fig. 4)

FIGURA 4

GRUPO I - CLASSE E REFORÇO, SEGUNDO O SEXO DO ALUNO

\begin{tabular}{c|c|c|c}
\hline & Meninos & Meninas & Total \\
\hline Classes & 81 & 100 & 181 \\
\hline Reforço & 19 & 25 & 44 \\
\hline
\end{tabular}

Classes x Sexo

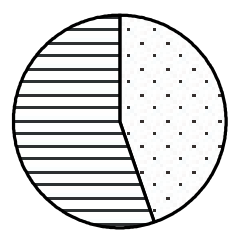

Reforço x Sexo

$\square$ Meninos

曰Meninas

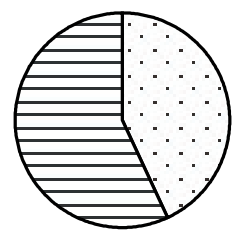

Diferentemente, a tendência nas quatro classes cujas professoras afirmavam "avaliar a criança como um todo" (Grupo 2) era de uma expressiva maioria de meninos indicados para reforço (Figs. 5 a 8).

FIGURA 5

JUSSARA - CLASSE E REFORÇO, SEGUNDO O SEXO DO ALUNO

\begin{tabular}{c|c|c|c}
\hline & Meninos & Meninas & Total \\
\hline Classe & 14 & 15 & 29 \\
\hline Reforço & 6 & 1 & 7 \\
\hline
\end{tabular}

Classe x Sexo

Reforço x Sexo )

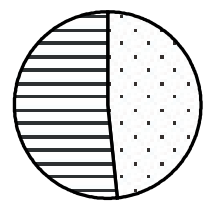

$\square$ Meninos

日Meninas

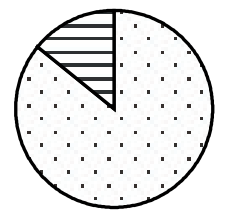


FIGURA 6

REBECA - CONCEITOS FINAIS, SEGUNDO O SEXO DO ALUNO

\begin{tabular}{c|c|c|c}
\hline & Meninos & Meninas & Total \\
\hline Classe & 13 & 16 & 29 \\
\hline NS & 5 & 5 & 10 \\
\hline
\end{tabular}

Classe x Sexo

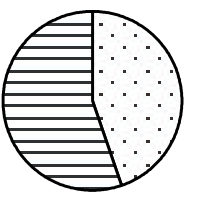

$\square$ Meninos

曰Meninas

\section{Conceitos NS x Sexo}

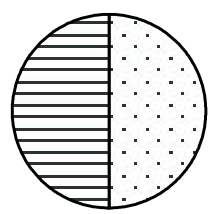

FIGURA 7

MARISA - CLASSE E REFORÇO, SEGUNDO O SEXO DO ALUNO

\begin{tabular}{c|c|c|c}
\hline & Meninos & Meninas & Total \\
\hline Classe & 16 & 16 & 32 \\
\hline Reforço & 8 & 3 & 11 \\
\hline
\end{tabular}

Classe x Sexo

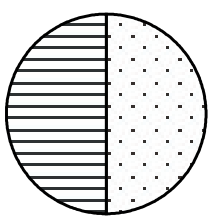

Reforço x Sexo

$\square$ Meninos

曰Meninas

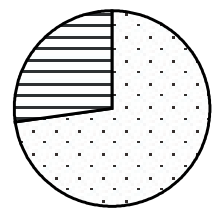


FIGURA 8

CLARA - CLASSE E REFORÇO, SEGUNDO O SEXO DO ALUNO

\begin{tabular}{c|c|c|c}
\hline & Meninos & Meninas & Total \\
\hline Classe & 14 & 16 & 30 \\
\hline Reforço & 6 & 4 & 10 \\
\hline
\end{tabular}

Classe x Sexo

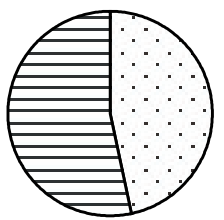

Reforço x Sexo

\section{$\square$ Meninos \\ 日Meninas}

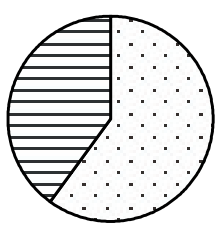

Os resultados indicam, portanto, que uma avaliação que não considere aspectos relativos ao comportamento do aluno ou aluna e procure ater-se a elementos de aprendizagem leva a um equilíbrio na proporção de meninos e meninas. As crianças do sexo masculino - em sua maioria de baixa renda e percebidas como negras - estariam recebendo conceitos negativos e indicações para atividades de reforço não por problemas de aprendizagem, mas pela maior dificuldade de manifestar comportamentos considerados corretos pela escola e pela professora da classe. Esta constatação é particularmente importante diante da literatura de enfoque conservador, que tem grande repercussão na mídia e entre as professoras. Estes autores afirmam diferenças inatas nos processos de aprendizagem entre os sexos, devido à conformação cerebral, com as mulheres mais propensas à comunicação e linguagem e os homens à orientação espacial e cálculos, ou afirmam a existência inevitável de trajetórias emocionais diferenciadas entre meninos e meninas. Com isso, acusam as escolas de estarem despreparadas para ensinar meninos (Pollack, 1999; Biddulph, 2002).

Os resultados desta pesquisa, no entanto, indicam que não estamos diante de uma diferença de aprendizagem, mas de comportamento, ao lado de uma grande indefinição de critérios de avaliação, o que pode estar criando dificuldades tanto para meninos, em sua maioria negros, que muito cedo constroem uma imagem de alunos incapazes de aprender; quanto para algumas 
meninas dedicadas e bem comportadas que nem chegam às turmas de reforço, mas que teriam muito a usufruir de uma atenção individualizada ou um apoio extra, se fosse considerada efetivamente sua aprendizagem.

Ao mesmo tempo, essa equalização entre os sexos na avaliação escolar não significa que as questões de gênero no âmbito da escola poderiam ser resolvidas apenas com a adoção de objetivos de aprendizagem bem definidos e de uma avaliação focalizada nessas metas. Isso resolveria simplesmente a questão dos objetivos do reforço, que poderiam voltar-se com exclusividade aos problemas de aprendizagem.

Como disseram todas as professoras de ambos os grupos, a maior parte dos problemas relativos à disciplina era com meninos. E uma vez que, entre as professoras que utilizavam critérios vagos de avaliação, a indisciplina era associada à percepção da criança como negra ou indígena, o debate sobre as desigualdades de gênero e raciais se torna central para modificar esse quadro. Pois, decerto, cabe também à escola ajudar todas as crianças a desenvolverem atitudes adequadas como alunos.

Assim, uma nova pergunta precisa ser feita: quais são essas atitudes adequadas? Como definir o comportamento esperado das crianças, de forma que seja um facilitador de sua aprendizagem e não apenas uma avaliação subjetiva na qual podem-se mesclar com facilidade preconceitos e pressupostos a respeito de masculinidades, feminilidades e pertencimento racial? Tanto quanto o conteúdo curricular, o significado de disciplina escolar e a definição de quais seriam os comportamentos adequados são um "produto discursivo histórico de uma configuração escolar e econômica singular", como afirmou Bernard Lahire (2003) a respeito de sucesso e fracasso escolares (p.54). Mais ainda, nas séries iniciais do ensino fundamental o debate sobre a disciplina dificilmente é feito de forma sistemática, por não ser visto como prioritário, uma vez que a crise de autoridade da escola em relação às crianças é menos aguda do que diante dos jovens. A definição de regras e comportamentos adequados fica em geral nas mãos de cada professora e, por consequência, varia segundo sua formação e seus valores. Se esse ponto não for alvo de uma reflexão crítica, é campo livre para a manifestação das diferentes formas de senso comum, que incluem preconceitos de classe, raça e gênero.

Tanto professoras do Grupo I quanto do Grupo 2 tendiam a perceber a necessidade de criar um processo de aprendizagem das posturas e com- 
portamentos que definiam como adequados à construção do conhecimento, em particular por lidarem com crianças muito pequenas, que iniciavam a vida propriamente escolar:

Umas crianças vêm de creche, mais aberta, aquela coisa menos sistematizada, algumas crianças demoram um pouquinho para perceber essa estrutura de escola, que a gente tem horário, que aqui não é só brincadeira, que brinca muito menos do que se brincava antes, que aqui a gente tem mais coisa para aprender. (Clara)

Mas a definição das posturas adequadas, de quem classificar como aluno indisciplinado, parecia ser muito difícil, e pelo menos algumas professoras do Grupo I mostraram perceber a subjetividade desse processo, como, por exemplo, Priscila e Meire, que classificaram na entrevista a pergunta sobre indisciplina de "difícil, horrível" e enfatizaram perceber múltiplos aspectos nos comportamentos de cada criança. Cabe lembrar que essas duas professoras haviam elaborado uma ficha de avaliação a ser discutida com as famílias, com perguntas bem delimitadas a respeito da aprendizagem e também do comportamento do aluno (onze questões, referentes a atenção, interesse, freqüência às aulas, organização dos materiais, comunicação oral e relacionamento com colegas e professora, cooperação e respeito às regras). Esse foi o caso de maior clareza de definição das posturas esperadas das crianças entre as professoras estudadas.

Nas entrevistas, quase todas as nove alfabetizadoras afirmavam que a classe inteira era agitada e esclareciam estar apontando como indisciplinados apenas "os casos mais graves", aqueles que destoavam do conjunto e atrapalhavam o desenvolvimento do trabalho de toda a turma: "O M., eu acho que é meu problema mais sério, porque ele é agitado, agressivo, não pára na carteira, ele bate e pula em cima do colega, as brincadeiras dele são violentas, ele é muito agressivo" (Jussara).

Nem sempre essas atitudes pareciam ter reflexo no aprendizado da própria criança, que conseguia bons resultados, embora atrapalhasse seus colegas e a dinâmica da classe, mais uma vez tanto nas palavras de professoras do Grupo I quanto do Grupo 2: "Por exemplo, esse ano, a que mais se destaca, quem é "a pimenta", é a G. Nossa! Tem dia que ela está atacada e aí ela ataca todo 
mundo. [E não atrapalha o desempenho dela?] Não. Ela é super rapidinha. Ela faz o que tem que fazer" (Clara).

Cabe reafirmar: com raras exceções, como nesse exemplo da classe de Clara, apenas meninos foram apontados como problemas sérios, classificados como "agressivos" ou "nervosos" e acusados de bater nos colegas. Já a indisciplina das meninas seria mais branda, ligada à dispersão, conversa e brincadeira: "Não é um problema de disciplina, é um problema porque elas conversam e isso atrapalha o rendimento delas. [...] Não seria aquele problema de disciplina, mas são meninas irrequietas, não um problema de disciplina" (Rebeca).

Enfim, mesmo entre as professoras que reuni no Grupo I, à clareza de critérios de avaliação de aprendizagem nem sempre correspondia uma clareza do que seria um comportamento adequado a ser construído pela escola, uma disciplina escolar, embaralhando os grupos de professoras antes estabelecidos. Apenas uma pesquisa de maior fôlego sobre o cotidiano das classes poderia explicitar os critérios efetivamente em uso e esclarecer até que ponto eles se relacionavam às concepções de gênero, aos preconceitos em relação às famílias pobres e à percepção racial das professoras sobre as crianças. As informações obtidas só me permitem afirmar que os meninos eram a fonte maior de dificuldades de disciplina, ainda que a própria definição dessas dificuldades fosse variável.

Como discuti (Carvalho, 2004a), com base no que já foi também explorado na literatura internacional (Connell, 1998, 2000; Kimell, 2000; MacAnGhail, 1995), diferentes formas de masculinidade e feminilidade são forjadas por meio das atitudes de contraposição às regras e à autoridade escolar. Se parece ser necessário, antes de mais nada, delimitar entre as professoras essas regras e exigências, um segundo passo seria uma compreensão mais profunda desses processos de contraposição à autoridade e seus significados para as próprias crianças. Tal aprofundamento poderia evitar a naturalização de comportamentos masculinos expressa em frases do tipo "os meninos são assim mesmo". E decerto ajudaria as professoras a construírem com seus alunos uma relação mais positiva com a escola, suas exigências e, consequentemente, também com o conhecimento escolar.

Finalmente, numa perspectiva de justiça social, a escola deve contribuir, para além de tudo isso, na construção de relações mais igualitárias e na aceitação de uma multiplicidade de formas de ser homem e ser mulher, menino e 
menina, branco, branca, negro, negra ou indígena. Isso só será possível com uma ampla discussão desses temas como parte da formação inicial e continuada das professoras, de forma que elas possam cumprir um papel transformador em relação às crianças e às famílias, por meio não apenas de questões relativas ao desempenho cognitivo, mas também de valores e práticas.

Pois mesmo as professoras que se mostraram atentas à necessidade de romper com modelos rígidos de gênero junto a suas classes, encontravam dificuldades, como contou Meire:

[A ideia de] que menina não pode jogar futebol, por exemplo. Então, a gente conversa muito com as crianças, dá bastante bronca. Por que não pode? Eu tenho três meninas na minha sala que adoram futebol. No começo, eles tiveram muita resistência, mas agora eles já brincam. Elas estão umas gracinhas. (Meire)

Creio que para entender as relações de gênero nas escolas, é necessário reafirmar que a construção de masculinidades e feminilidades entre crianças e jovens está longe da simples aprendizagem de normas únicas, sendo um processo com múltiplos caminhos, influenciados por classe, culturas, raça, e etnia; e que produz diversos resultados. Trata-se de encontros complexos entre crianças em desenvolvimento com uma instituição poderosa, mas ela mesma dividida, múltipla e em constante transformação, num processo nem sempre coincidente com outras dinâmicas sociais ou as histórias de outras instituições. Essa perspectiva, ao articular as questões de gênero às relações inter-raciais e de classe social, permite começar a entender o fato de que, na escolarização, a maioria das mulheres vai melhor que seus pares do sexo masculino, embora ocupem posições subordinadas no conjunto da sociedade. Isto porque assume não apenas a especificidade da escola perante outras instâncias sociais, mas também procura, sem perder de vista, as possibilidades de ação dos sujeitos, apreender os resultados contraditórios e mutantes das articulações entre diversas relações de poder em cada etapa da vida e em diferentes lugares sociais. Trazer esse olhar para a análise de dados empíricos, contudo, é um desafio permanente, uma tarefa complexa que apenas começa a ser enfrentada pelos estudos educacionais no Brasil. 


\section{REFERÊNCIAS BIBLIOGRÁFICAS}

ANGELUCCI, C. B. et al. O Estado da arte da pesquisa sobre fracasso escolar (|99|-2002): um estudo introdutório. Educação e Pesquisa, São Paulo, v. 30, n. I, p.5।-72, jan./abr. 2004.

BIDDULPH, S. Criando meninos. São Paulo: Fundamento, 2002.

CARVALHO, M. P. de. O Fracasso escolar de meninos e meninas: articulações entre gênero e cor/raça. Cadernos Pagu, Campinas, v.22, n. I, p.247-290, jan.jun. 2004.

. Mau aluno, boa aluna? Como as professoras avaliam meninos e meninas. Estudos Feministas, v. 9, n. 2, p.554-574, dez. 2001.

. Quem é negro, quem é branco: desempenho escolar e classificação racial de alunos. Revista Brasileira de Educação, Rio de Janeiro, v. 28, p.77-95, dez. 2005.

. Quem são os meninos que fracassam na escola? Cadernos de Pesquisa, São Paulo, v. 34, n. 121 , p. II-40, jan./abr. 2004a.

CONNELL, R. W. Disruptions: improper masculinities and schooling. In: KIMMEL, M.; MESSNER, M. (eds.) Men's lives. Boston: Allyn and Bacon, 1998. p. I 4 I - 154.

. The Men and the boys. Bekerley: UC Press, 2000.

HEY, V. et al. Boy's underachievement, special needs practices and questions of equity. In: EPSTEIN, D. et al. (eds.) Failing boys? Issues in gender and achievement, Buckingham: Open University Press, 1998. p. I32- 145.

JACKSON, D. Breaking out of the binary trap: boys' underachievement, schooling and gender relations In: EPSTEIN, D. et al. (eds.) Failing boys? Issues in gender and achievement. Buckingham: Open University Press, 1998. p.77-95.

KIMMEL, M. "What about the boys?" What the current debates tell us and don't tell us about boys in school: special report. (6 $6^{\text {th }}$. Annual Gender Equity Conference. Wellesley: Center for Research on Women's, jan.2000.)

LAHIRE, B. Sucesso escolar nos meios populares: as razões do improvável. São Paulo: Ática, 2003.

LINGARD, B.; DOUGLAS, P. Men engaging feminisms: pro-feminism, backlashes and schooling, Buckingham: Open University Press, 1999.

MaCanGHAILL, M. The Making of men: masculinities, sexualities and schooling. Buckingham: Open University Press, 1995. 
PATTO, M. H. S. A Produção do fracasso escolar: histórias de submissão e resistência. São Paulo: T. A. Queiroz, 1990.

PERRENOUD, P. Sucesso na escola: só o currículo, nada mais que o currículo! Cadernos de Pesquisa, São Paulo, n. I 19, p.9-27, julho 2003.

POLLACK, W. Meninos de verdade: conflitos e desafios na educação de filhos homens. São Paulo: Alegro, 1999.

SOARES, M. B. Letramento e alfabetização: as muitas facetas. Revista Brasileira de Educação, Rio de Janeiro, n. 25, p.5-17, jan./abr. 2004.

Recebido em: junho 2008

Aprovado para publicação em: fevereiro 2009 